\title{
Application GIS to Analyse Crime Risk in Bandung
}

\author{
Moh Dede, Iwan Setiawan and Asep Mulyadi \\ Universitas Pendidikan Indonesia, Jalan Dr. Setiabudhi no. 229, Bandung \\ desa96@student.upi.edu,iwansetiawan@upi.edu
}

Keywords: Crime, GIS, Security.

\begin{abstract}
This study aims to determine various factors are affected crime occurrence and discover crime risk distribution in Bandung using geographic information system (GIS) technology. It is to achieve suitable action against crime for mutual security. As quantitative research, the correlation of each factor is obtained from statistical test, then a decile rule used to know the value distribution. Eastman equation require score and weight from the correlation coefficient and value distribution for overlay analysis using GIS software to result crime risk distribution in Bandung. Correlation test identified that historical crime accidents, public facilities, and residence domination are most influence crime occurs, because crime needs suitable condition like place, time, and target. The resulted map of crime risk distribution shows 39.02 and 16.69 percent or more than half area of Bandung has very high and high risk. Based on the analysis, crime risk area agglomerate in the western and central of city are known as central business district. In addition, the temporal pattern of crime risk increase at 18.00 to $24.00 \mathrm{pm}$ who coverage almost three-fifths area of the city when citizen activity is highly.
\end{abstract}

\section{INTRODUCTION}

Application geographic information system (GIS) as a technology has grown in various scientific fields. SIG is able to prove itself as efficient and effective system in managing various spatial data and information, so a new information can be obtained according to user needs (Getis et. al., 2000). Crime as a pathological social and spatial phenomenon requires appropriate prevention with information technology to reduce the intensity, e.g. to mapping crime risk distribution using GIS (Eman et al., 2013). As a largest metropolitan in Indonesia, during 2014 2015 there are 9024 crime cases that occurred in Bandung, it listed the city as highest crime region in West Java Province (Bandung Police Dept., 2016). To response crime threat in Bandung, GIS have a role to determining crime risk locations through geospatial and geo-processing analyses based on various environmental and social factors are influence crime action in the region (Wing and Tynon, 2006).

Crime study using GIS has developed in several countries as part of internal security operations. In United States and Australia, crime analysis using GIS raises a term crime mapping, i.e. as spatial analysis processes of crime to obtain information about crime patterns, trends, and dynamics relating to location, time, and target or victim (Levine, 2006). Application GIS to analyse crime in a region gives the consequence that any spatial analysis of crime should use quantitative approach (Ratcliffe, 2010).

Previous studies about GIS in crime analysis were exercised by some researchers. Balogun et al. (2014) developed crime hotspots, areas deficient of security outfit, areas of overlap and areas requiring constant police patrol in Benin City using buffering analysis. Then, Olajuyigbe et al. (2016) revealed a transport route cutting through Akure metropolis is prone to crime activity using neighbourhood and statistical analyses with GIS. Other it study demonstrated a relationship between the property crime rate with household income and poverty in Malaysia using Likelihood Ratio Statistic (LRS) and Space-Time Normal Mixture Models by Zakaria and Rahman (2016).

Different from previous studies who only reveal some social and environmental factors using statistics, geo-statistics, and range analysis such as neighbourhood, LRS, and buffering analysis. This study uses statistical analysis result as input data for overlay analysis, so it will generate new information based on crime factors. Whereas, this study aims to determine various factors are affected crime occurrence and discover crime risk distribution in Bandung using GIS. The scope of factors are limited 
to eight essential variables from Stark (1987), Breetzke (2010), and FBI (2012).

Analysis about crime risk distribution in Bandung purposed to know a correlation between historical crime accidents, public facilities, residence domination, road network, security posts, land use, population density, and poverty distribution with crime action. so spatial nor temporal patterns of crime risk in the city can be obtained by overlay analysis using GIS. Correlation analysis using inferential statistics method is suitable with data characteristics and overlay analysis used is union to get all information (Raju, 2013). Based on the analysis, information about center of Bandung has very highly crime risk status. Then, region has far away from center and east of the city crime risk is decreasing.

\section{LITERATUR REVIEW}

\subsection{Crime and Geography}

Crime is an act that violates the rules or laws who prevailing in society and harms other persons, each violation has consequences such as penalty sanctions or other actions from law authorities (Buikhuisen, 1985). In the study of geography, crime phenomenon discusses on geography of crime as a part of human geography. It was born because each crime events are related by space, time, human activity, and pattern (Evans and Herbert, 2014). According to Stark (1987), FBI (2012), dan Breetzke (2010), there are several essential factors that cause a location to be risk of crime acts, such as (1) historical crime, (2) public facilities, (3) residence domination, (4) road network, (5) security posts, (6) land use, (7) population density, and (8) poverty distribution.

\subsection{GIS on Crime Analyse}

Geographic Information System (GIS) is a designed system to capture, store, manipulate, analyse, organize and display all types of geographical (geospatial) data of a region data be new information for decision making (Setiawan, 2010). GIS can be used as a tool in analysing and making decision in the security field, especially to mapping and crime analysis (Butorac and Marinović, 2017).

In some countries such as Australia, Canada, and the United States, spatial analysis of crime using GIS generally uses hotspots, statistics, and geo-statistics model (Ferreira, et. al., 2012). In Indonesia, the study of crime analysis using GIS generally only input data and serve information about crime sites, both conventional and web-based GIS (Maulana, 2016).

\section{METODHS}

Values for various factors are affect the distribution of crime in Bandung obtained by correlation analysis as a part of inferential statistics. The coefficient result is used as a value to weighting all factors and determining potential crime risk locations through overlay analysis on GIS software (Raju, 2013).

Each factor is determined by the correlation value with crime distribution using correlation analysis Pearson Product Moment Correlation formula (if the data is normally distributed) or Spearman Rank Correlation (if the data is not normal distribution) to resulting some value are used as a weight. For scoring or classifying scores in each factor using the decile rule (Chen, 2014). in detail the research schema and data acquisition presented in Figure 1.

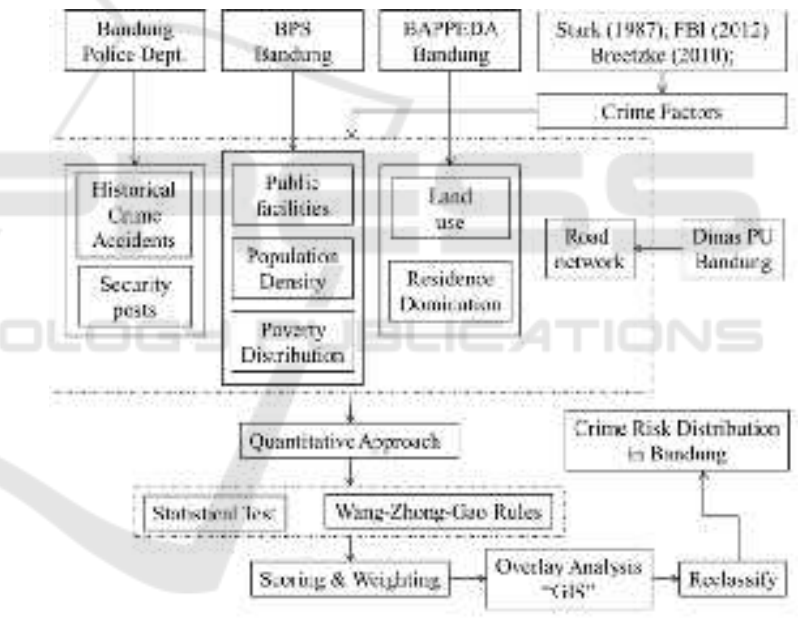

Figure 1: Research schema and data acquisition.

\section{RESULTS AND DISCUSSION}

\subsection{Factors are Influence Crime in Bandung}

In this study, each of the factors that influence crime is studied in the quantitative approach. For a first factor is historical crime accidents, obtained from crime locations relationship in 2014 and 2015. Based on the analysis, it is known that the historical crime accidents have correlation reach 0.947 which indicates very high trend of crime occurred in the same place. This further confirms that crime tends to 
be concentrated in certain places even near spaces with highly crime risk (Newton and Felson, 2015).

In this study, public facilities in Bandung as a second factor are limited to public work and space aspects such as famous places of worship, shopping centers, entertainment and tourism spot, health centers, transportation - train and bus station, airport - infrastructure, and educational places are often the center of people's activities (Batta et. al., 2014). Highly influence between public facilities distribution and crime in Bandung reach 0.827. it is means that attraction and open access to facilities for public give an opportunity crime action occurring (White, 1999).

To ensure the influence of human activities in space with crime is used residential land allocation in each sub-district as a third factor based on settlementland ratio. In Bandung, it ratio in each sub-district reach 68 to 98 percent in the western and central parts who shown a residence domination as urban characteristic with the correlation reaches 0.6. This condition causes urban residences have many ideal targets for crime offenders (Sayafzadeh and Hassani, 2014).

Road networks becomes the fourth factor, because it have main roles for human physical connectivity. The influence of road network to crime in Bandung reaches 0.51 or medium, the existence is often used by criminals to staging street or near road crimes. Beside it, road network also facilitates security personnels to patrol (Summers and Johnson, 2017).

The next factor is the distribution of security Polri and TNI - posts, Inequality the distribution causes the correlation with crime reaches 0.493 or medium. Existence of security posts should decrease opportunities for crime, it presence means that security personnels are always ready to maintain security can reduce fear of crime, so that its existence is used as a fifth factor related to crime in Bandung (Weisburd and Eck, 2004).

Based on assumption that a crime requires location suitability which is generally interpreted as land use, it is manifestation of environmental management by human as part of life empowerments decide it as the sixth factor who related to crime. In Bandung, correlation between land use and crime reach 0,209 or low, only residential land use type who can reaches of 0.6 or medium. Whereas for others land use have negative correlation, such as moor, rice field, empty land, forest, plantation, and concrete land with value between -0.169 to -0.48 . In addition, based on the results of chi-square test found that crime probability for each land use is not the same. It means confirming about crime risk tends occur in one type of land use i.e. residential land. Sypion-Dutkowska and Leitner (2017) said that crime trends occur settlement as suitable places.

Various modus operandi of urban crime generally targeting the public goods, so population density becomes the seventh factor. Correlation analysis result show the relationship between population density and crime in Bandung reached 0.126 or very low. The Highest urban population density and very low correlation with crime is indicates daily mobility of peoples is very high. Thus the population density is tend changing, but agglomerate around central business district (Hartman, 1950).

Finally, crime incidence is often associated with poverty distribution in a region, especially in urban area (Gümüş, 2003). In Bandung the correlation is only 0.035 or very low. This means that the poverty distribution is not able to justify an area in Bandung be vulnerable, thus it reinforcing that crime relate to suitable targets as a person or object as particularly attractive that are seen by the offender (Clarke and Felson, 1979).

\subsection{Crime Risk Distribution in Bandung}

Determining the crime risk distribution in Bandung begins with scoring and weighting any factors which related with crime. Uniforming the score can use descriptive statistic method, especially decile rule (Furqon, 2013). Whereas, each weight value is obtained from correlation analysis will be uniformed use Xiaodan et. al. (2010) model as shown in equation 1.

$$
\text { Weight }_{i}=\left(\frac{X_{i}-X_{\text {min }}}{X_{\text {max }}-X_{\text {min }}}\right) \times 5
$$

$$
\text { Crime Risk } \left.=\sum \text { (score } \mathrm{X} \text { weight }\right)
$$

The results of the equation 1 and decile rule are used as input for overlay analysis using GIS software (see table 2). Especially for land use, scoring is obtained from correlation value between land use and crime. Furthermore, the data in table 1 transform be crime risk value using Eastman method as in equation 3 (Riad et. al., 2011). The result of overlay analysis should be reclassify using quantile method to minimizing data deviation (Furqon, 2013), thus produce map of crime risk distribution in Bandung can be done. 


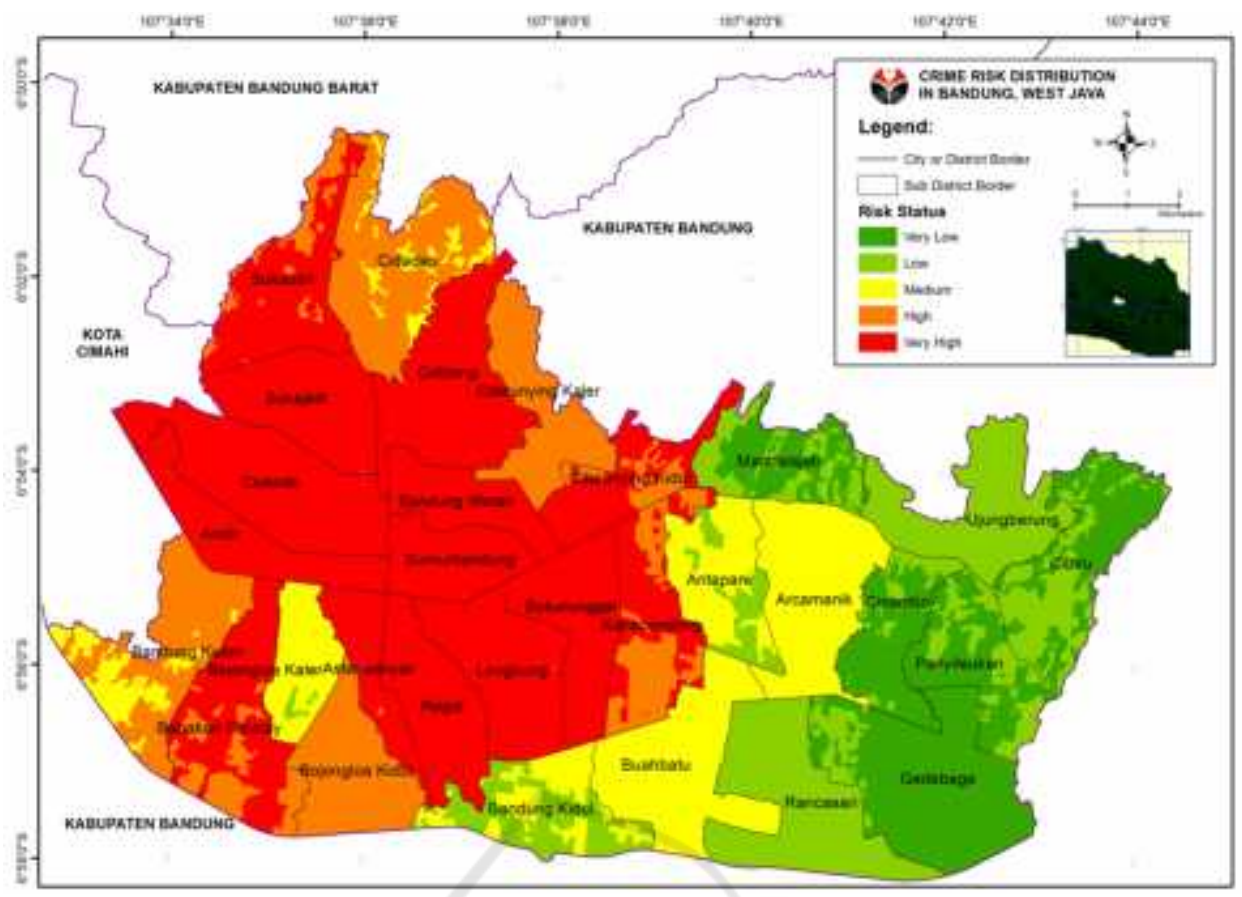

Figure 2: Crime risk distribution in Bandung.

Figure 2 shows the information about very high crime risk level in the western and central Bandung with $65.50 \mathrm{~km}^{2}$ area. Uniquely, the region is surrounded by areas with high levels of crime risk with $28.02 \mathrm{~km} 2$. When combined, the 55.72 percent of city area or $93.52 \mathrm{~km}^{2}$ have a status as prone to crime. The crime risk distribution in western and central Bandung as a center of growth is a normal phenomenon (Schuler, 2004). However, crime risk coverage which over half the city requires special handling, such as placement new security posts in any location, because it is easily factor than others (Weisburd and Eck, 2004).

Table 2: Scoring and weighting various factors of crime.

\begin{tabular}{|c|c|c|c|}
\hline Factors & Score & $\mathrm{R}$ & Weight \\
\hline Historical Crime & $1-5$ & 0.947 & 5.0 \\
\hline Public facilities & $1-5$ & 0,827 & 4.3 \\
\hline Residence domination & $1-5$ & 0.600 & 3.1 \\
\hline Road network & $1-5$ & 0.515 & 2.6 \\
\hline Security posts & $1-5$ & 0.493 & 2.5 \\
\hline Land use & $1-5$ & 0.209 & 1.0 \\
\hline Population Density & $1-5$ & 0.126 & 0.5 \\
\hline Poverty Distribution & $1-5$ & 0.035 & 0.0 \\
\hline
\end{tabular}

Crime risk distribution has a decrease trend towards the east, from Figure 2 it is known that some sub-districts in eastern Bandung such as Mandalajati, Gedebage, Panyileukan, Cinambo, and Cibiru are areas with low and very low crime risk status. This condition occurs due to the suitability of location and target for crime offenders is very minimal (Evans and Herbert, 2014).

Table 3: Dynamics of crime clock in Bandung.

\begin{tabular}{|c|c|c|c|c|}
\hline \multirow{2}{*}{$\begin{array}{c}\text { Crime } \\
\text { Risk }\end{array}$} & \multicolumn{4}{|c|}{ Area and Time $\left(\mathrm{km}^{2}\right.$ and 24 system $)$} \\
\cline { 2 - 5 } & $00-06$ & $06-12$ & $12-18$ & $18-24$ \\
\hline Very low & 22,07 & 22,66 & 22,66 & 22,66 \\
\hline Low & 26,24 & 26,01 & 24,36 & 24,36 \\
\hline Medium & 24,84 & 30,79 & 24,35 & 24,35 \\
\hline High & 29,06 & 24,02 & 30,71 & 30,71 \\
\hline Very High & 65,64 & 64,37 & 65,76 & 65,76 \\
\hline
\end{tabular}

In addition, through GIS the temporal pattern of crime risk distribution in Bandung can be determined based on crime clock data into four time from Bandung Police Dept. (2016). From the table 3. highest crime risk occurs at $18.00-24.00 \mathrm{GMT}+7$. In this time Bandung have high and very high crime risk status reaches $96,47 \mathrm{~km}^{2}$ or 57.48 percent of the city. This happens because at the time, Bandung people's activity mostly located in the streets, public spaces, and in a state of tired so that seen by the actors as suitable targets (Felson and Poulsen, 2003). 


\section{CONCLUSIONS}

Various factors such historical crime, public facilities, residence domination, road network, security posts, land use, population density, and poverty distribution have correlation with crime in Bandung. Using of geographic information systems (GIS) indicates that the highest risk areas agglomerate in central and western Bandung, so it has worry crime risk condition. In addition, it also found that toward the east, crime risk in Bandung decreased to a very low level. For the temporal pattern shows areas with high crime and very high risk increasing at $18.00-$ 24.00 GMT+7, it cover almost three-fifths of Bandung. This condition requires seriously efforts to reduce crime risk as part of mutual security in Bandung.

\section{ACKNOWLEDGEMENTS}

Special thanks for Unit of Criminal Investigation at Bandung Police Dept. who give chance to observe and some advice on this research for us. At least, for our friends (the 2014's squad of Geography Education UPI) on GIS course, especially for defence and security field and M. A. Widiawaty.

\section{REFERENCES}

Balogun, T. F., Okeke, H., Chukwukere, C., I., 2014. Crime mapping in Nigeria using GIS. Journal of Geographic Information System, 2014(6), 453-466.

Bandung Police Dept., 2016, Data tindak pidana tahun 2015, Unpublished, Bandung.

Batta, R., Lejeune, M., Prasad, S., 2014. Public facility location using dispersion, population, and equity criteria. European Journal of Operational Research, 234(3), 819-829.

Breetzke, G. D., 2010. A socio-structural analysis of crime in the city of Tshwane, South Africa. South African Journal of Science, 106 (11), 1-7.

Buikhuisen, W., Bontekoe, E. H. M., Plas-Korenhoff, C., 1985. Characteristics of criminals: the privileged offender. International Journal of Law and Psychiatry, 7, 301-313.

Butorac, K., Marinović, J., 2017. Geography of crime and geographic information systems. Journal of Forensic Science and Criminal Investigation, 2(4), 1-7.
Chen, J., 2014. GIS-based multi-criteria analysis for land use suitability assessment in City of Regina. Environmental Systems Research 43(13), 1-10.

Cohen, L., Felson, M., Social change and crime rate trends: a routine activity approach. American Sociological Review, 44(4), 588-608.

Eman, K., Györkös, J., Lukman, K., Meško, G., 2013. Crime mapping for the purpose of policing in Slovenia - recent developments. Journal of Criminal Investigation and Criminology, 64(3), 287-308.

Evans, D. J., Herbert, D. T., 2014. The geography of crime. Routledge, New York.

Felson, M., Poulsen, E., 2003. Simple indicators of crime by time of day. International Journal of Forecasting, 19(2003): 595-601.

Ferreira, J., João, P., Martins, J., 2012. GIS for crime analysis - geography for predictive models. The Electronic Journal Information Systems Evaluation, 15(1), 26-49.

Furqon, 2013, Statistika terapan untuk penelitian, Alfabeta, Bandung.

Getis, A., Drummy, P., Gartin, J., Gorr, W., Harries, K., Rogerson, P., Stoe, D., Wrigth, R., 2000. Geographic information science and crime analysis. URISA Journal, 12 (2), 7-14.

Hartman, G. W., 1950. The central business district - a study in urban geography. Economic Geography, 26(4), 237-244.

Levine, N., 2006. Crime mapping and the crime stat program. Geographical Analysis, 38(2006), 41-56.

Maulana, F. I., Prihatmanto, A. S., Kim, C. S., 2016. Design and implementation the concept of crowdsourcing on a web portal crime. In Proceeding 6th International Annual Engineering Seminar (InAES), 51-55.

Newton, A., Felson, M., 2015. Crime patterns in time and space: the dynamics of crime opportunities in urban areas. Crime Science, 4(11), 1-5.

Olajuyigbe, A., Omole, K., Bayode, T., Adenigba, A., 2016. Crime mapping and analysis in the core area of Akure, Nigeria. Journal of Remote Sensing and GIS, 5(178), 1-7.

Raju, P. L. N., 2013. Spatial data analysis. Satellite Remote Sensing and GIS Applications in Agricultural Meteorology, September (2013), 151-174.

Riad, P. H. S., Billib, M., Hassan, A. A., Salam, M. A., ElDin, M. N., 2011, Application of the overlay weighted model and Boolean logic to determine the best locations for artificial recharge of groundwater. Journal of Urban and Environmental Engineering, 5(2), 57-66.

Ratcliffe, J., 2010. Crime mapping: spatial and temporal challenges. In A.R. Piquero and D. Weisburd (eds.), Handbook of Quantitative Criminology, Springer Science and Business Media, LLC. 
Sayafzadeh, A., Hassani, M. J., 2014. The effects of land use in urban crime commitment in the unofficial settlement of Islam Abad, Zanjan. International Journal of Academic Research in Business and Social Sciences, 4(1), 474-489.

Schuller, N.,2004, Urban growth and community safety: developing the impact assessment approach for crime and disorder. Safer Communities, 3(4), 4-14.

Setiawan, I., 2010. Dasar-dasar sistem informasi geografis, Buana Nusantara, Bandung.

Stark, R., 1987. Deviant places: a theory of the ecology of crime. Criminology, 25(4), 893-909.

Summers, L., Johnson, S. D., 2017. Does the configuration of the street network influence where outdoor serious violence takes place? using space syntax to test crime pattern theory. Journal of Quantitative Criminology, 33(2), 397-420.

Sypion-Dutkowska, N., Leitner, M., 2017. Land use influencing the spatial distribution of urban crime: a case study of Szczecin, Poland. ISPRS International Journal of Geo-Information, 6(74), 1-23.

Weisburd, D., Eck, J., 2004. What can police do to reduce crime, disorder and fear?. The Annals of the American Academy of Political and Social Science, 593, 42-65.

White, R., 1999. Public spaces, social planning and crime prevention. Urban Policy and Research, 17(4), 301308.

Wing, M. G., Tynon, J., 2006. Crime mapping and spatial analysis in national forests. Journal of Forestry, September (2006), 293-298.

Xiaodan, W. Xianghao, Z., Pan, G., 2010, A GIS-based decision support system for regional eco-security assessment and its application on the Tibetian Plateau. Journal of Environmental Management, 91(2010), 1981-1990.

Zakaria, S., Rahman, N. A., 2016. The mapping of spatial patterns of property crime in Malaysia: normal mixture model approach. Journal of Business and Social Development, 4(1), 1-11. 